Viso - Cadernos de estética aplicada Revista eletrônica de estética

ISSN 1981-4062

No 19, jul-dez/2016

http://www.revistaviso.com.br/
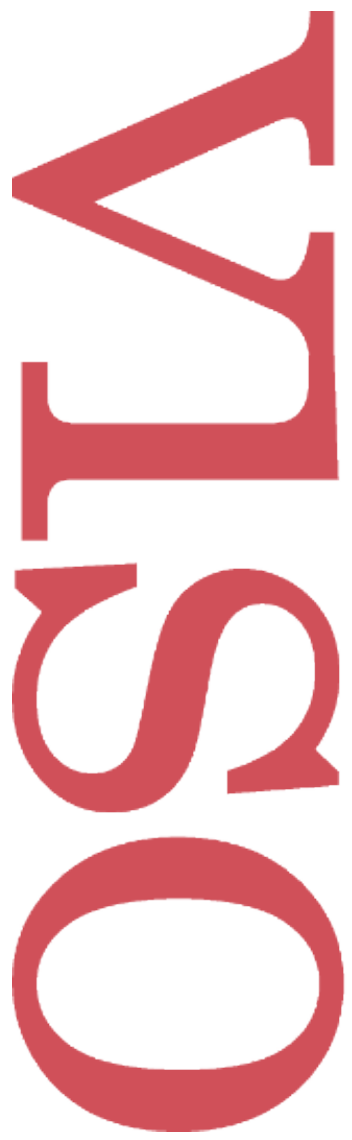

\title{
O problema da matriz: A herança hegeliana no fim da arte proposto por Arthur Danto \\ Imaculada Kangussu
}




\section{RESUMO}

O problema da matriz: A herança hegeliana no fim da arte proposto por Arthur Danto

Esse artigo é uma réplica ao texto de Rodrigo Duarte intitulado "Do 'sistema das artes' à ambiência pós-histórica: itinerários da estética contemporânea".

Palavras-chave: pseudomorfose - Verfransung - pluralismo estético - imagens técnicas

\section{ABSTRACT}

The Problem of Origin: The Hegelian Legacy of Arthur Danto's End of Art

This paper is a critical response to Rodrigo Duarte's "From the 'System of the Arts' to the Post-Historical Environment: Itineraries of Contemporary Aesthetics".

Keywords: pseudomorphosis - Verfransung - aesthetic pluralism - technical images 


\section{KANGUSSU, I. "O problema da matriz: A herença hegeliana no fim da arte proposto por Arthur Danto". In: Viso: Cadernos de estética aplicada, v. X, n. 19 (jul-dez/ 2016), pp. 19-28.}

DOI: 10.22409/1981-4062/v19i/227

Aprovado: 09.11.2016. Publicado: 28.12.2016.

(C) 2016 Imaculada Kangussu. Esse documento é distribuído nos termos da licença Creative Commons Atribuição-NãoComercial 4.0 Internacional (CC-BY-NC), que permite, exceto para fins comerciais, copiar e redistribuir o material em qualquer formato ou meio, bem como remixá-lo, transformá-lo ou criar a partir dele, desde que seja dado o devido crédito e indicada a licença sob a qual ele foi originalmente publicado.

Licença: http://creativecommons.org/licenses/by-nc/4.0/deed.pt_BR

Accepted: 09.11.2016. Published: 28.12.2016.

(C) 2016 Imaculada Kangussu. This document is distributed under the terms of a Creative Commons Attribution-NonCommercial 4.0 International license (CC-BY-NC) which allows, except for commercial purposes, to copy and redistribute the material in any medium or format and to remix, transform, and build upon the material, provided the original work is properly cited and states its license.

License: http://creativecommons.org/licenses/by-nc/4.0/ 
Esse ensaio teve origem no comentário que o grupo de trabalho em Estética da ANPOF convidou-me a fazer para o encontro de 2016, realizado em Ouro Preto, sobre o texto "Do 'sistema das artes' à ambiência pós-histórica: itinerários da estética contemporânea", de Rodrigo Duarte, no qual o autor destaca a influência hegeliana nas estéticas contemporâneas de Adorno, Danto e Flusser. Sendo assim, começo agradecendo ao grupo pelo convite, e muito especialmente ao Rodrigo, cujo artigo provocou as reflexões aqui apresentadas e de quem aproveitei algumas traduções ao citar Danto.

Em um primeiro momento, o foco estará na possibilidade de se pensar um fim da arte, conforme a proposta de Arthur Danto. "Um" e não "o" fim da arte, porque vale a pena destacar que o que sustenta a proposta de Danto é a ideia de que a arte tenha um fim que, uma vez realizado, implicaria o fim da própria arte. Em um segundo momento, nosso ensaio ressalta a herança hegeliana, confessa e assumida, presente na teoria do filósofo norte-americano. No capítulo IV da compilação da Estética de Hegel, são apresentadas as "formas da arte" - que correspondem às variações nos modos de expressão do espírito - e o desenvolvimento destas formas - que começa com a "arte simbólica", seguida pela "arte clássica" e é fechado pela "arte romântica". A arte simbólica encontra sua melhor expressão na arquitetura, as colossais construções egípcias e mesopotâmicas são os exemplos do maior peso dos elementos materiais sobre os espirituais. A clássica, na escultura grega, onde espírito e matéria parecem ter encontrado o equilíbrio perfeito; e a romântica, na pintura, na música e na poesia, com crescentes graus de abstração e de espiritualidade. Nesse desenrolar hegeliano do espírito absoluto, a arte pode encontrar sua morte diante de formas mais imateriais de expressões do espírito. Mais uma vez vale destacar que, também em Hegel, o fim da arte está imediatamente ligado à ideia de que a arte possua um fim, isto é, uma finalidade (a de representar o espírito sensivelmente) que, uma vez alcançado, tornaria a arte desnecessária.

Sem pretender esgotar o assunto, este breve escrito concentra-se em dois textos: em "O fim da arte"1, de Arthur C. Danto, e no "Plano geral da estética" ${ }^{2}$, de Hegel; e, para concluir, argumenta em uma direção distinta daquela tomada pelos dois notáveis filósofos.

Já na introdução de "O fim da arte", é posta a suposição de que o destino da arte é alcançar sua própria filosofia, e que este é alcançado quando a arte transforma-se, ela mesma, em filosofia. "Sem dúvida, esta foi uma tese de Hegel, e algumas de suas visões inspiraram o presente ensaio"3, registra o autor. Resumindo sucintamente, Danto considera que o destino da arte já foi atingido: a chamada arte conceitual já se transformou em filosofia, com isso a história da arte chegou ao fim e, portanto, a arte contemporânea seria "pós-histórica". 
No sistema hegeliano, como se sabe, a arte é o primeiro momento ou a primeira figura do espírito, superada por outras figuras mais elevadas: primeiro pela religião e, depois, pela filosofia. E isso porque, enquanto a obra de arte é uma espécie de matéria espiritualizada e remete ao imaterial através da própria materialidade, a religião apresenta o espírito enquanto espírito, mas ainda necessitando uma representação particular para se reconhecer. Para Hegel, arte e religião são representações antecipadas da filosofia. Possuem conteúdos de verdade, mas simbolizados em representações particulares. O espírito só alcança a própria essência quando alcança o conceito de si mesmo no pensamento filosófico - e pode então dispensar o véu das formas simbólicas (artísticas e religiosas) que lhe são inadequadas. O movimento de superação da arte por figuras mais elevadas do espírito, conforme proposto pela filosofia hegeliana, é análogo ao ultrapassamento da arte por um novo nível mais elevado de consciência filosófica pensado por Danto. Conforme este, "autoconsciência é o grande atributo do espírito absoluto, do qual, pensa Hegel, arte, filosofia e religião, são os momentos principais e talvez únicos". ${ }^{4}$ Como a tese hegeliana do fim da arte está ligada ao fato de ela depender dos sentidos e necessitar da matéria sensível, "a superioridade da filosofia é que ela não tem tal necessidade". ${ }^{5}$

Como Hegel, para propor o fim da arte Danto também precisa incluí-la em uma história progressiva, com princípio, meio e fim, aristotelicamente, nessa ordem. E constrói essa história partindo da ideia de Gombrich segundo a qual a história da pintura é a história de uma conquista gradual das técnicas de representação. O famoso historiador da arte considera que essa conquista é realizada quando a capacidade mimética alcança o estágio de reproduzir "fielmente" a natureza, em The Image and the Eye e em The Story of $A r t{ }^{6}$ É a partir deste ponto de excelência na reprodução mimética que, segundo Danto, "a história da arte, ou pelo menos a da pintura concebida como tal, realmente chega ao fim". ${ }^{7}$ Antes de prosseguir a apresentação da proposta historiográfica do fim da arte de Danto, ressalto que não é esta a conclusão de Gombrich. Ao contrário, os últimos capítulos de $A$ história da arte têm o título de "Revolução permanente" [Permanent Revolution], "Em busca de novos padrões" [In Search of New Standards] e "Uma história sem fim" [A Story without End]. Quer dizer, o fato de a pintura mimética ter tido uma história de progresso no que diz respeito à representação não implica, para Gombrich, o fim da arte.

O progresso da arte consistiria, para Danto, no desenvolvimento da capacidade dos artistas de duplicarem a realidade de modo "exato". Essa capacidade é apresentada tendo como metáfora o que Wittgenstein denomina, no Tractatus Logico-Philosophicus, como "ciência total natural", que seria uma figuração logicamente isomórfica do mundo "concebido como a soma total dos fatos". Continuando com as palavras de Danto sobre Wittgenstein, "a história da ciência poderia então ser lida como o progressivo encolhimento da distância entre representação e realidade [...] de modo que tudo poderia, finalmente, ser conhecido assim como, na pintura, tudo poderia finalmente ser mostrado". ${ }^{8}$ É possível, portanto, julga Danto, pensar "o futuro da arte construído em 
termos de progresso representacional"', capaz de encolher a distância entre representação e realidade.

Entretanto, observa o filósofo norte-americano, depois do surgimento do impressionismo, uma nova teoria fez-se necessária, na medida em que artistas não estavam mais buscando a qualidade da representação e sim a da expressão. Conforme Gombrich, "Van Gogh desejava que suas pinturas expressassem o que ele sentia, e se distorções ajudavam-no a alcançar esse propósito ele iria usar distorções". ${ }^{10} \mathrm{Em} \mathrm{1902,} \mathrm{Croce}$ publicou a Estética come scienza dell'expressione. E, "desde que pudessem existir pinturas puramente expressivas e consequentemente não representacionais, a representacionalidade [desculpem-me o neologismo para traduzir representationality] deve desaparecer da definição de arte". ${ }^{11}$ O problema, para Danto, é que, se isto acontecer, quer dizer, se a definição da arte não estiver mais ligada à representação e sim à expressão e, com isso, o progresso da arte for dissociado do progresso da representação mimética, não se pode pensar em uma história progressiva da arte, uma vez que, conforme se pode ver no trecho a seguir,

simplesmente não há a possibilidade de uma sequência de desenvolvimento com o
conceito de expressão, como havia com o conceito de representação mimética [...] não
há base para dizer que podemos expressar agora o que mal, ou de modo algum,
poderíamos antes, como poderíamos dizer que agora podemos mostrar coisas que
antes poderíamos mostrar mal, ou de modo algum. Assim, a história da arte não tem um
futuro do tipo que possa ser extrapolado, seja como for, contra o paradigma do
progresso: ela apenas quebra-se em uma sequência de atos individuais, um depois do
outro [...] É claro que pode haver uma história do aprendizado de expressar
sentimentos, como através de um tipo de terapia, mas isto pertenceria à história geral
da liberdade, com nenhuma aplicação à arte. Heidegger disse que, na análise filosófica
dos sentimentos, nenhum passo foi dado desde a Retórica, de Aristóteles. ${ }^{12}$ A incomensurabilidade da expressão torna possível uma perspectiva radicalmente descontínua da história da arte - e impossibilita se pensar em progresso. Apenas pensada como "representação" a arte pode ter uma história adequada ao modelo de progresso que atinge seu fim. Pois, "se pensarmos a arte como sendo simplesmente expressão, ou comunicação de sentimentos, como Croce fez, bem, não pode haver uma história deste tipo e a questão do fim da arte não tem qualquer aplicação, porque o conceito de expressão caminha com uma espécie de incomensurabilidade". ${ }^{13}$ A questão levantada por Danto é que se, por um lado, a arte pode ser vista como trabalho de representação com um desenvolvimento histórico próprio, por outro lado, essa ideia é insuficiente para defini-la.

Assim, o que emerge dessa dialética é que, se devemos pensar na arte como tendo um fim, precisamos de uma concepção da história da arte que seja linear, mas uma teoria da arte que seja suficientemente geral para incluir outras representações além do tipo que a pintura ilusionista melhor exemplifica: representação literária, por exemplo, e mesmo a música. [§] Agora, a teoria de Hegel satisfaz todas essas exigências. Seu pensamento requer que haja continuidade histórica genuína e até mesmo um tipo de 
progresso. O progresso em questão [...] é um tipo de progresso cognitivo, onde se entende que a arte, progressivamente, aproxima-se desta forma de cognição. Quando a cognição é alcançada, realmente não há mais nenhum argumento para - nenhuma necessidade da - arte. Arte é um estágio de transição [transitional stage] no advento de um certo modo de conhecimento. A pergunta então é sobre que tipo de conhecimento pode ser este e a resposta, que a princípio deve soar desapontadora, é que se trata do conhecimento do que a arte é [...] a arte termina com o advento de sua própria filosofia. ${ }^{14}$

Danto aceita e faz uso da ideia de um processo de "continuidade histórica genuína", apresentado na filosofia hegeliana, e leva em conta a existência de um "progresso cognitivo" na dimensão estética para pensar as obras de arte de seu tempo quando, em suas palavras,

os objetos aproximam-se do zero e a teoria sobre eles aproxima-se do infinito, de modo que, virtualmente, o que existe no fim é teoria, arte sendo enfim vaporizada em uma ofuscação de puro pensamento sobre si mesma e permanecendo apenas como o objeto de sua própria consciência teórica [...]

Se algo como esse ponto de vista tem a mais remota chance de ser plausível, é possível supor que a arte chegou a um fim. Obviamente, haverá ainda a fatura de arte, mas os fazedores de arte, vivendo no que gosto de chamar período "pós-histórico" da arte, trarão à existência obras que carecem da importância ou do significado históricos que viemos a esperar delas desde muito tempo. O estágio histórico da arte está concluído quando é sabido o que a arte é e o que ela significa. ${ }^{15}$

Deste modo, vemos que, na estética de Danto, a história da arte chegou ao final porque, julga ele, já "é sabido o que a arte é e o que ela significa". Esta era sua finalidade, a autoconsciência, e será o seu fim. Pode ser interessante agora uma volta à matriz hegeliana, para se perceber melhor as relações entre a arte e o processo cognitivo que parece poder levá-la à morte (em Hegel) ou à sua pós-história (em Danto).

No "Plano geral da estética", considera-se que "a função da arte consiste em conciliar, numa livre totalidade, a ideia e a representação sensível [...] a ideia representada numa forma concreta e sensível" ${ }^{16}$ No início dessa história, a ideia ainda é abstrata, está indeterminada, sem clareza: "não é ainda uma realidade precisa que se manifesta em sua verdadeira forma", observa Hegel, "está-se ainda em presença da ideia não determinada, sem a forma que ainda procura [...]. Em sua inquietude e insatisfação, a ideia evolui e expande-se na matéria, procura torná-la adequada". ${ }^{17}$ Mas como a ideia não é clara, tentando expressar o que ainda não sabe o que é, o artista tortura a matéria, buscando nela a forma do que Ihe é obscuro. Nas palavras de Hegel,

A ideia indefinida, a ideia infinita apropria-se da forma, e esta apropriação de uma forma que lhe não convém tem todos os aspectos de uma violência: na verdade, só maltratada e contundida, uma forma é apropriada pela ideia a que não convém [...]. 
É verdade que a forma sofre uma violência, que é, por assim dizer, devorada. Mas menos, com isso, se adequa, de qualquer modo, a um conteúdo. Aliás, se a matéria natural ainda não se adapta verdadeiramente ao conteúdo, é também porque o próprio conteúdo não se presta ainda a essa adaptação [...]

É o que caracteriza a arte simbólica ou oriental.

Esta arte pertence à categoria do sublime, e o sublime define-se pelo esforço de definir o infinito. ${ }^{18}$

Depois desse primeiro momento, na tentativa de dar forma a uma ideia que ainda não tem forma, Hegel considera que a forma de exprimir o espiritual atinge a perfeição na arte clássica, quando é alcançada a adequação entre matéria e ideia, porque esta é clara e concreta. A fraqueza e insuficiência da arte clássica residem não na dimensão estética e sim no fato de o espírito ainda precisar ser expresso através da matéria - no fato de a arte ser apenas arte. $\mathrm{Na}$ fase seguinte, a arte romântica rompe com a harmonia entre conteúdo e forma, é "a interioridade consciente de si própria que aparece como o conteúdo verdadeiramente real da arte". ${ }^{19} \mathrm{Na}$ marcha triunfante do Espírito Absoluto, escreve Hegel, "a arte simbólica ainda procura o ideal, a arte clássica atingiu-o e a romântica ultrapassou-o". ${ }^{20}$

Se, na perspectiva da fenomenologia do espírito, i.e, no processo de o espírito manifestar-se fenomenicamente, a história parece muito bem narrada, podem-se colocar algumas questões a partir da perspectiva da arte e da dimensão estética. E um importante ponto de distinção pode ser encontrado nas diferentes temporalidades atuantes nestas duas instâncias. Conforme ressalta Danto, em passagem já citada no presente ensaio, "precisamos de uma concepção da história da arte que seja linear [...] que haja continuidade histórica genuína e até mesmo um tipo de progresso". A proposta de Danto, e de sua matriz hegeliana, só funciona em uma história linear, progressiva, capaz de levar a arte a atingir o conhecimento do que ela, a arte, é.

E aqui podem surgir duas questões. A primeira diz respeito ao tempo contínuo e linear, ao tempo "seta" moderno (distinto do tempo circular dos mitos), paradigma que a partir, pelo menos, das investigações freudianas parece ultrapassado pela ideia de um tempo em rede que envolve, simultaneamente, passado, presente e futuro. "Nas Teses sobre o conceito de história", Walter Benjamin também assinala a obsolescência do registro temporal linear e contínuo e propõe uma temporalidade onde passado, presente e futuro estão enredados. Na obra das Passagens, Benjamin diferencia o passado que passou [Vergangene] do passado vivo [Gewesenen], e distingue o presente espremido entre passado e futuro do presente que ele denomina "tempo do agora" [ Jetztzeit]. ${ }^{22} \mathrm{O}$ trânsito entre os diferentes tempos é estabelecido por sincronia e não por linearidade contínua. "Cada presente é determinado pelas imagens que Ihe são sincrônicas; cada Agora é o Agora de uma cognoscibilidade determinada". ${ }^{23}$ Benjamin salienta que o conhecimento 
está ligado a um núcleo temporal que existe tanto no objeto conhecido quanto no sujeito que conhece.

Assim, considerando que o presente pode lançar uma luz sobre o passado - e vice versa -, pode-se voltar às relações entre espírito e matéria, conforme propostas na teoria hegeliana, e indagar sobre a possível permanente existência de artistas (simbólicos?) que enfrentam a matéria com ideias indefinidas, com desejo de expressar o infinito, o absoluto e outras ideias infiguráveis, de artistas que encontram a forma perfeita de exprimir o espiritual na matéria (clássicos?), e de artistas conceituais que ultrapassam a materialidade (românticos?). Do ponto de vista da arte, parece difícil determinar o progresso alcançado pela Ópera dos três vinténs em relação a, por exemplo, Hamlet, ou na superioridade desta obra sobre Antígona, por exemplo.

A outra questão diz respeito à ideia de o conhecimento inteligível ter se sobreposto à matéria sensível, de a obra de arte ter a função de produzir um tipo de conhecimento que, uma vez alcançado, iria torná-la dispensável. Se, por um lado, na perspectiva de Hegel, isso de fato acontece, por outro lado rebaixar, na experiência estética, a sensação ao conceito me parece colocar em risco o equilíbrio que a mesma é capaz de criar. Como também desconsiderar a existência de um conhecimento que depende da sensação. Desde a escolástica "é preciso dizer que a verdade encontra-se tanto no intelecto quanto nos sentidos, de maneiras distintas". ${ }^{24} \mathrm{E}$ ainda, desconsiderar que a experiência estética produz um tipo de conhecimento bastante específico da situação na qual ela se desenvolve, através do efeito de alienação: as obras de arte podem produzir - em quem é sensível a elas - a experiência de alienação de um mundo alienado. "Seu distanciamento da mera existência torna-se a medida do que há nesta de errado e de ruim". 25

São estes breves argumentos que apresento contra a ideia da morte da arte: o primeiro é relativo à necessidade de adoção de um tempo linear e contínuo para sustentar o movimento de progresso inerente a esta ideia; o segundo diz respeito à implícita postulação, nela presente, de uma ultrapassagem do sensível pelo inteligível, i.e, por um modo específico de conhecer que desconsidera tanto o conhecimento sensível quanto o conhecimento produzido pela união de matéria e espírito, pela experiência da forma estética através das obras de arte.

Quanto ao movimento futuro e imprevisível da arte, sua dinâmica parece-me bem atraente na fala de um personagem de ficção, Stephen Dedalus, alter ego de Joyce: "desejo apertar nos braços a beleza que ainda não surgiu no mundo". ${ }^{26}$

\footnotetext{
* Imaculada Kangussu é professora do Departamento de Filosofia da UFOP.
} 
1 DANTO, A. C. "The End of Art". In: The Philosophical Disenfranchisement of Art. New York: Columbia University Press, 2005, pp. 81-115. Publicado pela primeira vez em 1984.

2 HEGEL, G. W. F. "Plano geral da estética". In: Hegel. Coleção Os pensadores. São Paulo: Abril, 1974, pp. 145-162.

${ }^{3}$ DANTO. A. C. Op. cit., p. 83.

${ }^{4}$ Idem. "The Future of Aesthetics". In: What Art Is. New Haven \& London: Yale University, 2013, p. 149.

${ }^{5}$ Ibidem, p. 124.

${ }^{6} \mathrm{GOMBRICH}$, E. H. The Story of Art. London, New York: Phaidon Press, 2006.

${ }^{7}$ DANTO, A. C. "The End of Art". Op. cit, p. 86.

${ }^{8}$ Ibidem, pp. 86-87.

9 Ibidem, p. 97.

${ }^{10} \mathrm{GOMBRICH}$, E. H.Op. cit., p.423.

${ }^{11}$ DANTO, A. C. "The End of Art". Op. cit., p. 103.

12 Ibidem, p. 103-104. Grifo do autor.

${ }^{13}$ Ibidem, p. 106.

${ }^{14}$ Ibidem, p. 107.

${ }^{15}$ Ibidem, p. 111. Grifo do autor.

${ }^{16}$ HEGEL, G. W. F.Op. cit., p. 145.

17 Ibidem, p. 149.

${ }^{18}$ Ibidem, p. 150.

${ }^{19}$ Ibidem, p. 153.

${ }^{20}$ Ibidem, p. 155.

21 "O passado, o presente e o futuro são entrelaçados pelo fio do desejo". FREUD, S. "Escritores criativos e devaneios" [1907]. In: Pequena coleção das obras de Freud. Livro 30. Rio de Janeiro: Imago, 1976, p. 105.

${ }^{22}$ BENJAMIN, W. Das Passagen-Werk. Gesammelte Schriften, Band V. Frankfurt: Suhrkamp, 1993 $\left\{F^{*} 6\right\}$, p. 1006 e $[K$ 1, 3], p. 491.

${ }^{23}$ Ibidem, [N 3, 1].

${ }^{24}$ AQUINO, T. "Question disputéé de la vérité", q. 1, a. 9. In: IMBACH, R.; MÉLÉARD, M.-H. (orgs.) Philosophes médiévaux des XII e XIV siécles. Paris: Union Générale d'Editions, 1986, p. 92.

${ }^{25}$ ADORNO, T. W. "Lírica e sociedade". In: Benjamin, Habermas, Horkheimer, Adorno. Coleção Os pensadores. São Paulo: Abril Cultural, 1983, p. 195.

${ }^{26}$ JOYCE, J. A Portrait of the Artist as a Young Man. London: Penguin, 1996. 